\title{
Biological significance of tumor budding at the invasive front of human colorectal carcinoma cells
}

\author{
YUSRA, SHUHO SEMBA and HIROSHI YOKOZAKI \\ Division of Pathology, Department of Pathology, Kobe University Graduate School of Medicine, Kobe, Japan
}

Received January 24, 2012; Accepted April 10, 2012

DOI: $10.3892 /$ ijo.2012.1459

\begin{abstract}
At the invasive front of colorectal carcinoma (CRC), the existence of tumor budding (TB), the detachment and migration of small clusters of tumor cells from the neoplastic epithelium, correlates with high incidence of local invasion and distant metastasis; however, the molecular background of TB is still unknown. In human CRC-derived SW480 cells, $\mathrm{CD}_{133^{+}}$cells showed cancer stem cell (CSC)-like properties, high tumorigenicity and pluripotency. By a comparative study of gene expression between CD133+ and CD133- SW480 cells, high sensitivity against transforming growth factor- $\beta$ (TGF- $\beta$ ) was suggested in $\mathrm{CD}_{133}{ }^{+} \mathrm{SW} 480$ cells. Interestingly, treatment with recombinant TGF- $\beta 1$ increased the numbers of cells expressing CD133 and SNAI1. Furthermore, in CD133- SW480 cells, the SNAI1-induced epithelial-mesenchymal transition (EMT) restored the population of $\mathrm{CD}_{133}{ }^{+}$cells and increased tumorigenicity, cell motility/invasiveness and matrix metalloproteinase 2 (MMP2) expression. In stage II CRC tissues, TB was associated with increased levels of SNAI1 expression as well as high incidence of metachronous lymph node metastasis post-surgical resection. These findings suggest that TGF- $\beta$ regulates not only the induction of EMT but also the restoration of CSCs in CRC. The tumor microenvironment at the invasive front is important for the formation of tumor buds in CRC.
\end{abstract}

\section{Introduction}

Tumor budding (TB) initially termed as sprouting, is a morphologic phenomenon observed at the advancing edge of neoplasms and is characterized by isolated or small clusters of tumor cells that detach from the neoplastic epithelium and migrate a short distance into the neoplastic stroma, which may explain the more aggressive behavior of the tumors which show this feature $(1,2)$. In human colorectal carcinoma (CRC), evaluation of TB is therefore a useful prognostic marker $(3,4)$, however, the detailed molecular mechanisms of TB formation remain unknown.

Correspondence to: Dr Shuho Semba, Division of Pathology, Department of Pathology, Kobe University Graduate School of Medicine, 7-5-1 Kusunoki-cho, Chuo-ku, Kobe 650-0017, Japan

E-mail: semba@med.kobe-u.ac.jp

Key words: tumor budding, CD133, transforming growth factor- $\beta 1$, SNAI1, colorectal carcinoma
Recently, accumulating evidence has demonstrated that CRC consists of a heterogeneous population of cells and contains a subset of cells that initiate and propagate tumors with high efficiency (5). Since these cells, called cancer stem cells (CSC) or cancer-initiating cells, exhibit not only stem cell properties such as self-renewal and multipotency but also resistance to chemotherapy or radiotherapy (6), there is an urgent need to elucidate the molecular background underlying the maintenance of colorectal CSCs. Numerous colorectal CSC markers have been identified, including Lgr5 $(7,8)$, CD44 $(9,10)$, aldehyde dehydrogenase (ADH) (11) and, most recently, CD133 (12). Indeed, lineagetracing studies have shown that $\mathrm{CD} 133^{+}$cells are located at the base of crypts in the intestine and generate the entire intestinal epithelium, suggesting that $\mathrm{CD} 133^{+}$cells are intestinal stem cells and susceptible to transformation into tumors that retain a fraction of mutant $\mathrm{CD}_{133}{ }^{+} \mathrm{CSCs}(13)$. $\mathrm{CD} 133^{+}$colorectal CSCs grew exponentially for more than one year in vitro as undifferentiated tumor spheres in serum-free medium, maintaining the ability to engraft and reproduce the same morphological and antigenic pattern of the original tumor (14). A clinicopathological study on $\mathrm{CRC}$ reported that patients with high $\mathrm{CD} 133^{+} \mathrm{CSC}$ had significantly poorer overall survival $(15,16)$.

As described above, TB at the invasive front and CD133+ CSCs within the tumor have been established as prognostic markers of human CRC, respectively; nevertheless, the association between TB and CSCs is still unknown. In this study, we investigated the nature of colorectal CSCs and attempted to reproduce $\mathrm{TB}$ in vitro and in vivo to examine whether cells making up tumor buds might have CSC-like properties, or CSCs at the invasive front might form tumor buds.

\section{Materials and methods}

Cell culture, magnetic bead separation and gene transfection. Human CRC-derived SW480 cells obtained from American Type Culture Collection (Manassas, VA, USA) were maintained in RPMI-1640 (Invitrogen, Carlsbad, CA, USA) containing $10 \%$ fetal bovine serum (FBS; Nichirei, Tokyo, Japan) and antibiotics. For magnetic bead separation, SW480 cells were labeled with anti-CD133 microbeads (Miltenyi, Auburn, CA, USA) and separated on an autoMACS separator (Miltenyi). The human SNAI1-coding region (NM_005985) was subcloned into the pCX4bsr vector to generate pSNAI1 as described previously (17). Using effectene transfection reagent (Qiagen, Hilden, Germany), pSNAI1 and empty vector (EV) were transduced 
into CD133- SW480 cells according to the manufacturer's instruction.

Tumor sphere formation and flow cytometry. Cells were maintained in DMEM/F12 (BD Biosciences, Franklin Lakes, NJ, USA) supplemented with $20 \mathrm{ng} / \mathrm{ml}$ of epidermal growth factor (EGF; Sigma, St. Louis, MO, USA), $40 \mathrm{ng} / \mathrm{ml}$ of basic fibroblast grow th factor (bFGF; Sigma) and $2 \mathrm{ng} / \mathrm{ml}$ of transforming growth factor- $\beta 1$ (TGF- $\beta 1$; Sigma). Tumor spheres were obtained by mixing the cells and Matrigel (BD Biosciences)-containing DMEM/F12 (Invitrogen) and plated on a 4-well chamber slide for more than four weeks. For flow cytometric analysis, cells were washed with phosphate-buffered saline (PBS) and supplemented with anti-human CD133 antibody conjugated with R-phycoerythrin (Miltenyi). The cell pellets were washed with $1 \%$ bovine serum albumin (BSA) in PBS and fixed using $1 \%$ paraformaldehyde. Expression of CD133 was analyzed using a FACS Calibur cytometer (BD Biosciences).

RT-PCR and quantitative real-time RT-PCR. The primer sets used in this study are listed in Table I. RT-PCR was performed with a One-Step RT-PCR assay kit (Qiagen). Thirty minutes after incubation at $50^{\circ} \mathrm{C}$, each $25 \mu \mathrm{l}$ reaction mixture containing $10 \mathrm{ng}$ of total RNA was amplified for 30 cycles with the following regimen: denaturation at $94^{\circ} \mathrm{C}$ for $30 \mathrm{sec}$; annealing at $58^{\circ} \mathrm{C}$ for $30 \mathrm{sec}$ and extension at $72^{\circ} \mathrm{C}$ for $1 \mathrm{~min}$. The products underwent electrophoresis on $2 \%$ agarose gel. Quantitative real-time RT-PCR was conducted with an ABI PRISM 7700 Sequence Detection System (Applied Biosystems, Foster City, CA, USA) and QuantiTect SYBR Green RT-PCR kit (Qiagen). The real-time cycler conditions were reverse transcription at $50^{\circ} \mathrm{C}$ for $30 \mathrm{~min}$, followed by 45 cycles of denaturation at $94^{\circ} \mathrm{C}$ for $15 \mathrm{sec}$, annealing at $52^{\circ} \mathrm{C}$ for $30 \mathrm{sec}$ and elongation at $72^{\circ} \mathrm{C}$ for $30 \mathrm{sec}$. The threshold cycle $\left(\mathrm{C}_{\mathrm{t}}\right)$ was standardized to the sample glyceraldehyde-3-phosphate dehydrogenase $(G A P D H)$ value $\left(\Delta \mathrm{C}_{\mathrm{t}}=\right.$ Gene $\left.\mathrm{C}_{\mathrm{t}}-G A P D H \mathrm{C}_{\mathrm{t}}\right)$, and this value was then compared between two kinds of cells using the $\Delta \Delta \mathrm{C}_{\mathrm{t}}$ method, which was then used to determine the fold change $\left(=2^{\wedge}\left[-\Delta \Delta C_{t}\right]\right)$.

Immunofluorescence. Cells and tumor spheres were fixed with $4 \%$ paraformaldehyde and then incubated with blocking solution containing $1 \%$ BSA. Formalin-fixed and paraffin-embedded tissue sections were also used. The antibodies used are as follows: CD133 (Miltenyi), TGF- $\beta$ type 1 (TGFBR1; Santa Cruz Biotechnology, Santa Cruz, CA, USA) and type 3 receptors (TGFBR3; Abcam, Cambridge, MA, USA), MUC2 (Santa Cruz Biotechnology), villin (Thermo Scientific, Walthan, MA, USA), MUC5Ac (Santa Cruz Biotechnology), Chromogranin A (CgA; Dako, Glostrup, Denmark), Snail (SNAI1; Abcam), E-cadherin (CDH1; BD Biosciences), vimentin (VIM; Epitomics, Burlingame, CA, USA) and $\alpha$-smooth muscle actin (SMA; Abcam). Cy2- or Cy3-conjugated antibody against rabbit/mouse IgGs (GE Healthcare, Little Chalfont, UK) were used as secondary antibodies. The nuclei were stained with 4,6-diamidino-2-phenylindole (DAPI).

Tumorigenicity test. Cells $\left(1 \times 10^{3}-10^{6}\right.$ cells/200 $\mu$ l Matrigel) were inoculated subcutaneously into the back of 12-week-old severe combined immunodeficiency (SCID) mice (Japan Clea, Tokyo, Japan). Four weeks after inoculation, the mice were
Table I. The primer sets used for RT-PCR and quantitative real-time RT-PCR in this study.

\begin{tabular}{|c|c|}
\hline Gene & Sequence \\
\hline$C D X 2$ & $\begin{array}{l}\text { F: 5'-GGA ACC TGT GCG AGT GG-3' } \\
\text { R: 5'-TTC CTC CGG ATG GTG ATG TA-3' }\end{array}$ \\
\hline$C D 133$ & $\begin{array}{l}\text { F: 5'-GCG TGA TTT CCC AGA AGA TA-3' } \\
\text { R: 5'-CCC CAG GAC ACA GCA TAG AA-3' }\end{array}$ \\
\hline$C D 10$ & $\begin{array}{l}\text { F: 5'-ACT CTA TGC AAC CTA CGA TG-3' } \\
\text { R: 5'-TGT CAA AGT TGC CGT AAC GG-3' }\end{array}$ \\
\hline$M U C 2$ & $\begin{array}{l}\text { F: 5'-CGA AAC CAC GGC CAC AAC GTC T-3' } \\
\text { R: 5'-GAC CAC GGC CCC GTT AAG CA-3' }\end{array}$ \\
\hline$C D 44$ & $\begin{array}{l}\text { F: 5'-CAG TCA CAG ACC TGC CCA ATG-3' } \\
\text { R: 5'-AAC CTC CTG AAG TGC TGC TCC-3' }\end{array}$ \\
\hline TGFBRI & $\begin{array}{l}\text { F: 5'-ATT CCT CGA GAC AGG CCG TT-3' } \\
\text { R: 5'-CTG GTC CAG CAA TGA CAG C-3' }\end{array}$ \\
\hline TGFBR3 & $\begin{array}{l}\text { F: 5'-AGT ATG GAG CAG TTA CTT CAT T-3' } \\
\text { R: 5'-AGC AAG GTA ATT GAG TGA GAG-3' }\end{array}$ \\
\hline $\mathrm{CDH} 1$ & $\begin{array}{l}\text { F: 5'-GCT GGA GAT TAA TCC GGA CA-3' } \\
\text { R: 5'-GCT GGC TCA AGT CAA AGT CC-3' }\end{array}$ \\
\hline VIM & $\begin{array}{l}\text { F: 5'-CTT CGC CAA CTA CAT CGA CA-3' } \\
\text { R: 5'-GCT TCA ACG GCA AAG TTC TC-3' }\end{array}$ \\
\hline$M M P 2$ & $\begin{array}{l}\text { F: 5'-ACG ACC GCG ACA AGA AGT AT-3' } \\
\text { R: 5'-ATT TGT TGC CCA GGA AAG TG-3' }\end{array}$ \\
\hline$M M P 9$ & $\begin{array}{l}\text { F: 5'-GAC AAG CTC TTC GGC TTC TG-3' } \\
\text { R: 5'-TCG CTG GTA CAG GTC GAG TA-3' }\end{array}$ \\
\hline$G A P D H$ & $\begin{array}{l}\text { F: 5'-TGA TGA CAT CAA GAA GGT GGT GA-3' } \\
\text { R: 5'-TCC TTG GAG GCC ATG TGG GCC-3' }\end{array}$ \\
\hline
\end{tabular}

F, forward; R, reverse.

sacrificed and paraffin-embedded tumor sections were used for hematoxylin and eosin (H\&E) staining and immunohistochemistry (IHC). Initiating cell frequency was calculated using the extreme limiting dilution analysis (ELDA) (18).

cDNA microarray analysis. Total cellular RNA was extracted using RNeasy Mini Kit (Qiagen) according to the manufacturer's recommendations from $\mathrm{CD}_{133^{+}}$and CD133- SW480 cells that were sorted based on their expression for CD133 using autoMACS separator (Miltenyi). The concentration of RNA was determined by measuring the absorbance at $260 \mathrm{~nm}$ in a spectrophotometer. A cDNA microarray was performed by Human Expression Array version 2.0 (Agilent Technologies, Palo Alto, CA, USA). The in vitro transcription, oligonucleotide array hybridization and scanning were performed according to Takara Bio protocols (Takara Bio, Otsu, Japan). Briefly, doublestranded cDNA was synthesized from total RNA, and was labeled with RNA Fluorescence Labeling Core Kit (Takara Bio). Arrays were then scanned with GeneArray scanner (Agilent Technologies) to obtain image and signal intensities. After data normalization, significance analysis of microarray (SAM) plot 
A

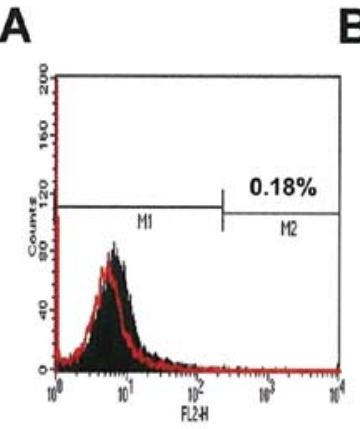

B

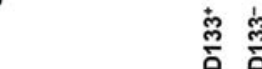

总

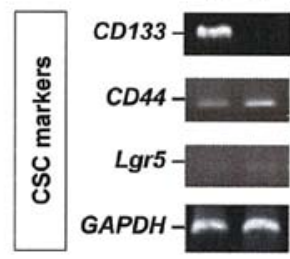

C
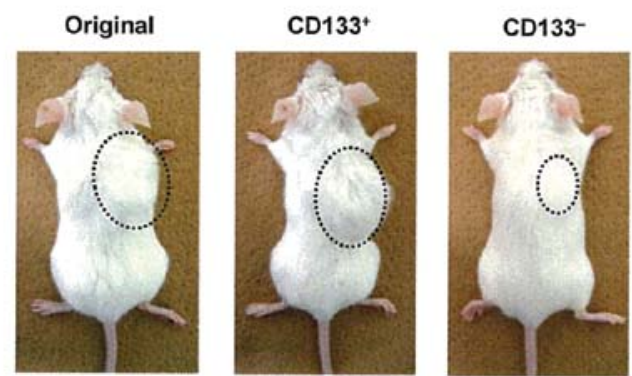

D

\begin{tabular}{|c|c|c|c|}
\hline \multicolumn{4}{|c|}{ Number of tumors/numbers of injections } \\
\hline Cells per & Original & $\mathrm{CD}^{133^{+}}$ & CD133- \\
\hline Injection & Incidence (\%) & Incidence (\%) & Incidence $(\%)$ \\
\hline $1 \times 10^{7}$ & $4 / 4 \quad(100)$ & N.E. & $4 / 4(100)$ \\
\hline $1 \times 10^{6}$ & $4 / 4(100)$ & $2 / 2(100)$ & $4 / 4(100)$ \\
\hline $1 \times 10^{5}$ & $4 / 4(100)$ & $4 / 4(100)$ & $3 / 4$ \\
\hline $1 \times 10^{4}$ & $3 / 4 \quad(75)$ & $4 / 4 \quad(100)$ & $3 / 4$ \\
\hline $1 \times 10^{3}$ & $3 / 4 \quad(75)$ & $2 / 2(100)$ & $0 / 4$ \\
\hline Frequency & $1 / 3522$ & $>1 / 418^{*}$ & $1 / 36092^{\star}$ \\
\hline
\end{tabular}

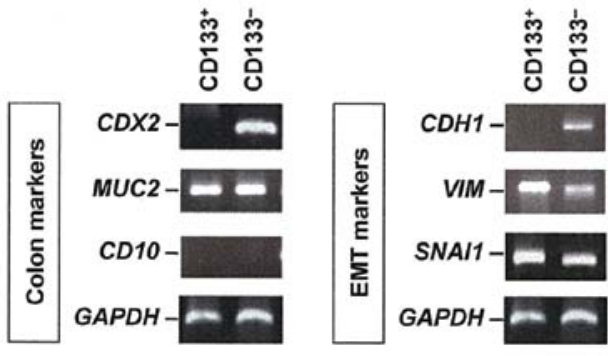

E
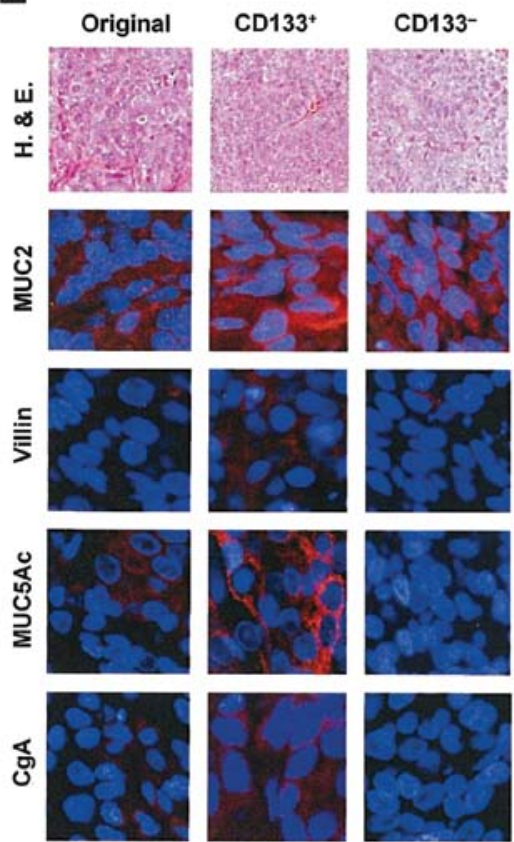

Figure 1. Characteristic of $\mathrm{CD}_{133^{+}} \mathrm{SW} 480$ cells. (A), Result of flow cytometric analysis. The percentage of $\mathrm{CD} 133^{+} \mathrm{SW} 480$ cells was $0.18 \%$. Red line is the negative control. (B), Expressions of CSC markers (CD133, CD44 and Lgr5), colon markers (CDX2, MUC2 and CD10) and EMT markers (CDH1, VIM and SNAII) in $\mathrm{CD}_{133^{+}}$and CD133- SW480 cells. (C), Gross appearance of tumors derived from SW480 cells (original, CD133' and CD133'). (D), Results of limiting dilution assay. SW480 cells (original, $\mathrm{CD}_{133^{+}}$and CD133-) were inoculated into SCID mice subcutaneously with Matrigel. Initiating cell frequency was calculated using ELDA as described in Materials and methods. Included in calculation, assumption of $100 \mathrm{CD} 133^{+}$cells initiate 0 tumor in 2 injections. (E), IHC of MUC2, villin, MUC5Ac and CgA expressions in tumors derived from SW480 cells (original, CD133' and CD133).

analysis was performed and significantly altered genes were identified in accordance to the manufacturer's protocol (http:// chem.agilent.com).

Wound healing assay and invasion assay. For the wound healing assay, cultured cells at almost $100 \%$ confluence were serum-starved for $12 \mathrm{~h}$. After scratching the monolayer, cells were washed with PBS and then cultured for $24 \mathrm{~h}$. The distance of scratching in $0 \mathrm{~h}$ minus in $24 \mathrm{~h}$ was measured. Cell invasion activities were estimated using cell culture inserts with an $8-\mu \mathrm{m}$ pore size membrane coated with Matrigel. Aliquots of $2.5 \times 10^{5}$ cells were placed in upper chamber with serum-free medium, whereas the lower chamber was loaded with RPMI-1640 containing 10\% FBS. After 48-h incubation, the non-invading cells were removed, and the invaded cells on the lower surface of the membrane were counted.

Tissue samples and IHC. A total of 59 formalin-fixed and paraffin-embedded stage II CRC samples obtained from Kobe
University Hospital (Kobe, Japan) were collected. At the time of surgical resection, these cases were diagnosed as stage II CRC; however, metachronous lymph node metastasis was detected in 32 cases of the patients. Informed consent was obtained from all patients and the study was approved by the Kobe University Institutional Review Committee. Statistical analysis was performed using StatView 5.0.1. (SAS, Cary, NC, USA). TB was determined according to the criteria of Ueno et al (2). IHC was performed using the labeled streptavidin-biotin kit (Dako) with antibodies against CDX2 (Biogenex, San Ramon, CA, USA) and SNAI1 (Abcam).

\section{Results}

CD133 recognizes colorectal CSCs. $\mathrm{CD} 133^{+}$cells at the colon crypts are tissue stem cells that differentiate into enterocytes, enteroendocrine cells and goblet cells (7). In CRC-derived SW480 cells, the frequency of CD133 ${ }^{+}$cells was only $0.18 \%$ (Fig. 1A); however, there were discrepancies in the expressions 
Table II. The genes differentially down-regulated in CD133- SW480 cells in comparison with CD133+ ${ }^{+}$SW80 cells.

\begin{tabular}{|c|c|c|c|}
\hline GDB accession no. & Description & $\log 2$ ratio & Gene symbol \\
\hline NM_130436 & Dual-specificity tyrosine-phosphorylation regulated kinase $1 \mathrm{~A}$ & -2.63 & DYRK1A \\
\hline NM_007224 & Neurexophilin 4 & -2.63 & NXPH4 \\
\hline NM_003528 & Histone cluster $2, \mathrm{H} 2 \mathrm{be}$ & -2.52 & HIST2H2BE \\
\hline NM_019055 & Roundabout homolog 4 & -2.33 & ROBO4 \\
\hline NM_002471 & Myosin, heavy chain 6 , cardiac muscle, alpha & -2.30 & MYH6 \\
\hline NM_013397 & Prickle homolog 4 & -2.24 & PRICKLE4 \\
\hline NM_001926 & Defensin, alpha 6 & -2.20 & DEFA6 \\
\hline NM_004475 & Flotillin 2 & -2.13 & FLOT2 \\
\hline NM_000691 & Aldehyde dehydrogenase 3 family, memberA1 & -2.11 & ALDH3A1 \\
\hline NM_018557 & Low density lipoprotein-related protein 1B & -2.06 & LRP1B \\
\hline NM_003865 & HESX homeobox 1 & -2.03 & HESX1 \\
\hline NM_014552 & Grainyhead-like 1 & -2.01 & GRHL1 \\
\hline NM_005376 & v-myc homolog 1 , lung carcinoma derived & -1.99 & MYCL1 \\
\hline NM_031944 & Mix1 homeobox-like 1 & -1.99 & MIXL1 \\
\hline NM_000422 & Keratin 17 & -1.98 & KRT17 \\
\hline NM_152597 & Fibrous sheath interacting protein 1 & -1.97 & FSIP1 \\
\hline NM_001007527 & LMBR 1 domain containing 2 & -1.96 & LMBRD2 \\
\hline NM_005503 & Amyloid beta precursor protein-binding, family A, member 2 & -1.96 & APBA2 \\
\hline NM_033297 & NLR family, pyrin domain containing 12 & -1.95 & NLRP12 \\
\hline NM_024325 & Zinc finger protein 343 & -1.94 & ZNF343 \\
\hline NM_003965 & Chemokine(C-C motif) receptor-like 2 & -1.93 & CCRL2 \\
\hline NM_182539 & t-complex-associated-testis-expressed 1 & -1.91 & TCTE1 \\
\hline NM_052910 & SLIT and NTRK-like family, member 1 & -1.91 & SLITRK1 \\
\hline NM_147192 & Diencephalon/mesencephalon homeobox 1 & -1.91 & DMBX1 \\
\hline NM_001781 & CD69 molecule & -1.90 & CD69 \\
\hline NM_022436 & ATP-binding cassette, sub-family G, member 5 & -1.90 & ABCG5 \\
\hline NM_006613 & GRB2-related adaptor protein & -1.90 & GRAP \\
\hline NM_007031 & Heat shock transcription factor 2 binding protein & -1.90 & HSF2BP \\
\hline NM_152437 & Zinc finger protein 664 & -1.90 & ZNF664 \\
\hline NM_021200 & Pleckstrin homology domain containing, family B, member 1 & -1.88 & PLEKHB1 \\
\hline NM_004067 & Chimerin (chimaerin) 2 & -1.88 & $\mathrm{CHN} 2$ \\
\hline NM_012426 & Splicing factor $3 \mathrm{~b}$, subunit 3 & -1.88 & SF3B3 \\
\hline NM_014055 & Intraflagellar transport 81 homolog & -1.85 & IFT81 \\
\hline NM_000658 & Autoimmune regulator & -1.83 & AIRE \\
\hline NM_017659 & Glutaminyl-peptide cyclotransferase-like & -1.83 & QPCTL \\
\hline NM_004807 & Heparan sulfate 6-O-sulfotransferase 1 & -1.82 & HS6ST1 \\
\hline NM_172312 & Sapiens sperm associated antigen 8 & -1.82 & SPAG8 \\
\hline NM_014598 & Suppressor of cytokine signaling 7 & -1.81 & SOCS7 \\
\hline NM_138343 & Kinesin light chain 4 & -1.81 & KLC4 \\
\hline NM_014942 & Ankyrin repeat domain 6 & -1.80 & ANKRD6 \\
\hline NM_006983 & Matrix metallopeptidase 23B & -1.79 & MMP23B \\
\hline NM_173561 & Unc-5 homolog C-like & -1.79 & UNC5CL \\
\hline NM_005276 & Glycerol-3-phosphate dehydrogenase 1 & -1.79 & GPD1 \\
\hline NM_004612 & Transforming growth factor, beta receptor 1 & -1.78 & TGFBR1 \\
\hline NM_001079802 & Fukutin & -1.78 & FKTN \\
\hline NM_000419 & Integrin, alpha $2 b$ & -1.76 & ITGA2B \\
\hline NM_001032297 & Zinc finger protein $658 \mathrm{~B}$ & -1.76 & ZNF658B \\
\hline NM_198582 & Kelch-like 30 & -1.76 & KLHL30 \\
\hline NM_004403 & Deafness, autosomal dominant 5 & -1.74 & DFNA5 \\
\hline NM_003277 & Claudin 5 & -1.74 & CLDN5 \\
\hline NM_005557 & Keratin 16 & -1.73 & KRT16 \\
\hline NM_017649 & Cyclin M2 & -1.73 & CNNM2 \\
\hline
\end{tabular}


Table II. Continued.

\begin{tabular}{|c|c|c|c|}
\hline GDB accession no. & Description & $\log 2$ ratio & Gene symbol \\
\hline NM_001076787 & Tumor protein p53 inducible protein 11 & -1.73 & TP53I11 \\
\hline NM_182983 & Hepsin & -1.73 & HPN \\
\hline NM_053017 & ADP-ribosyltransferase 5 & -1.70 & ART5 \\
\hline NM_031431 & Component of oligomeric golgi complex 3 & -1.70 & COG3 \\
\hline NM_022124 & Cadherin-like 23 & -1.70 & $\mathrm{CDH} 23$ \\
\hline NM_153282 & Hyaluronoglucosaminidase 1 & -1.69 & HYAL1 \\
\hline NM_203471 & Lectin, galactoside-binding, soluble, 14 & -1.69 & LGALS14 \\
\hline NM_003243 & Transforming growth factor, beta receptor III & -1.68 & TGFBR3 \\
\hline NM_021603 & FXYD domain containing ion transport regulator 2 & -1.68 & FXYD2 \\
\hline NM_001085 & Serpin peptidase inhibitor, clade A, member 3 & -1.68 & SERPINA3 \\
\hline NM_133467 & CBP-interacting transactivator, Glu/Asp-rich C-terminal domain 4 & -1.67 & CITED4 \\
\hline NM_018207 & Tripartite motif-containing 62 & -1.67 & TRIM62 \\
\hline NM_054028 & Acyl-malonyl condensing enzyme 1-like 2 & -1.67 & AMAC1L2 \\
\hline NM_001312 & Cysteine-rich protein 2 & -1.65 & CRIP2 \\
\hline NM_018334 & Leucine rich repeat neuronal 3 & -1.65 & LRRN3 \\
\hline NM_017525 & CDC42 binding protein kinase gamma & -1.64 & CDC42BPG \\
\hline NM_001013706 & Lipid storage droplet protein 5 & -1.64 & LSDP5 \\
\hline NM_005495 & Solute carrier family 17 , member 4 & -1.64 & SLC17A4 \\
\hline NM_138576 & B-cell CLL/lymphoma 11B & -1.63 & BCL11B \\
\hline NM_173849 & Goosecoid homeobox & -1.63 & GSC \\
\hline NM_001518 & General transcription factor II, i & -1.62 & GTF2I \\
\hline NM_004851 & Napsin A aspartic peptidase & -1.62 & NAPSA \\
\hline NM_001771 & CD22 molecule & -1.62 & $\mathrm{CD} 22$ \\
\hline NM_001782 & CD72 molecule & -1.61 & CD72 \\
\hline NM_014574 & Striatin, calmodulin binding protein 3 & -1.60 & STRN3 \\
\hline NM_032528 & ST6 beta-galactosamide alpha-2,6-sialyltranferase 2 & -1.60 & ST6GAL2 \\
\hline NM_001011545 & BTB and CNC homology 1 & -1.60 & BACH1 \\
\hline NM_007225 & Neurexophilin 3 & -1.60 & NXPH3 \\
\hline NM_000529 & Melanocortin 2 receptor & -1.59 & $\mathrm{MC} 2 \mathrm{R}$ \\
\hline NM_016315 & GULP, engulfment adaptor PTB domain containing 1 & -1.59 & GULP1 \\
\hline NM_017576 & Kinesin family member 27 & -1.59 & KIF27 \\
\hline NM_033508 & Glucokinase (hexokinase 4) & -1.59 & GCK \\
\hline
\end{tabular}

of the other colorectal CSC markers CD44 and Lgr5 (Fig. 1B). Similar results were detected in the other human CRC cell lines (data not shown). We also examined the differential expressions of colon markers $(C D X 2, M U C 2$ and $C D 10)$ and epithelialmesenchymal transition (EMT) markers (CDH1, VIM and SNAII) between $\mathrm{CD}^{133^{+}}$and CD133- SW480 cells. Interestingly, $\mathrm{CD}_{133}{ }^{+} \mathrm{SW} 480$ expressed extremely low levels of $C D X 2$ and $C D H 1$, whereas they expressed higher levels of VIM and SNAII (Fig. 1B). These findings suggested that CD133 ${ }^{+}$SW480 cells were characterized by dedifferentiation and EMT.

In addition, $\mathrm{CD} 133^{+} \mathrm{SW} 480$ cells demonstrated high potential as CSCs: the tumorigenicity of CD133+ SW480 cells was 86 times higher than that of CD133- SW480 cells (Fig. 1C and D). The xenografts developed in SCID mice showed pluripotency by expressing the enterocyte makers MUC2 (colon), villin (small intestine), MUC5Ac (stomach) as well as the enteroendocrine marker CgA (Fig. 1E). Since CDX2 is a transcription factor that regulates development and differentiation of the intestinal epithelium (19), we transduced CDX2-expression vector (pCDX2) into $\mathrm{CD} 133^{+} \mathrm{SW} 480$ cells as a colorectal CSC differentiation model. Induction of CDX2 not only promoted cell differentiation and branch formation in three-dimensional culture but also effectively decreased tumorigenicity (unpublished data). Thus, we concluded that CD133 recognizes colorectal CSCs.

TGF- $\beta$ restores $C D 133^{+} S W 480$ cells and induces EMT. To identify genes that are responsible for the maintenance of CSC-like properties, a comparative study of gene expression profiles was performed using $\mathrm{CD}_{133^{+}}$and CD133- $\mathrm{SW} 480$ cells (Table II). Among the down-regulated genes ( $>1.6$-fold) in CD133- SW480 cells, we focused on the type 1 (TGFBRI) and type 3 (TGFBR3) TGF- $\beta$ receptor genes. We confirmed that expressions of TGFBR1 and TGFBR3 in CD133+ ${ }^{+}$SW480 cells were higher than those in CD133 cells at the mRNA and protein levels (Fig. 2A and B). 
A

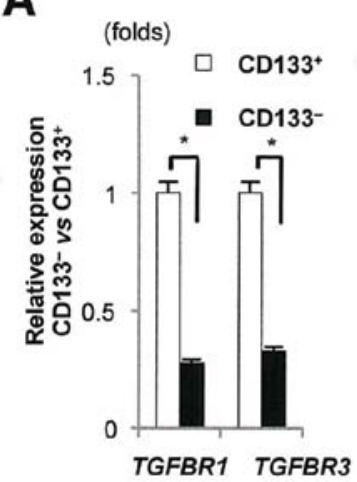

B

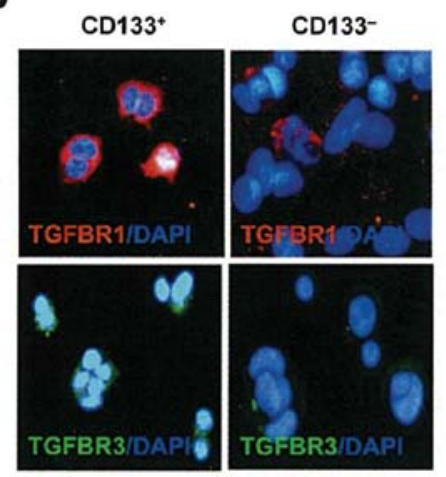

C
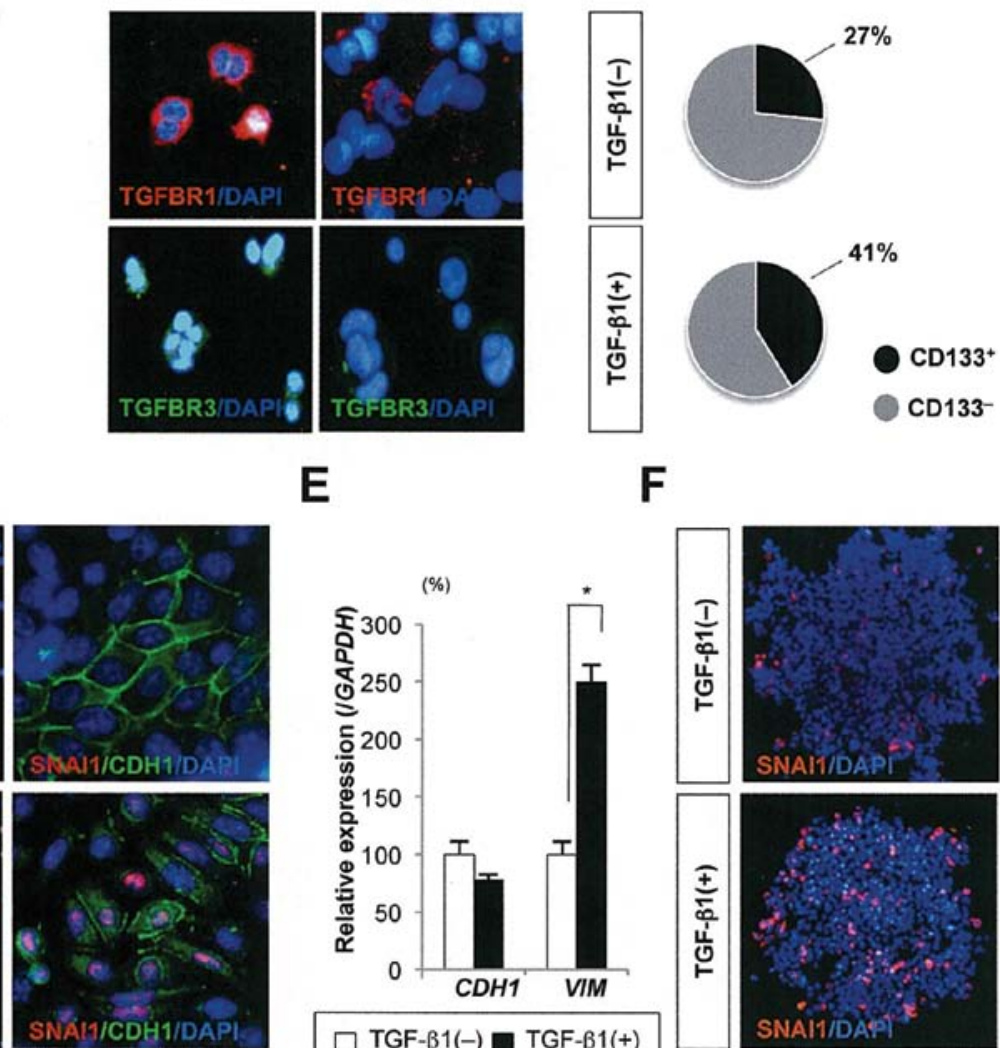

E

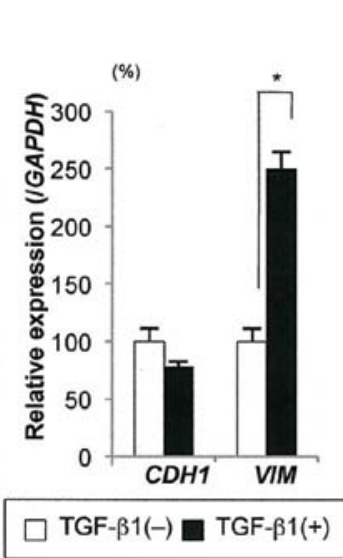

$\mathbf{F}$

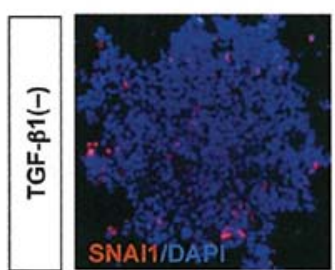

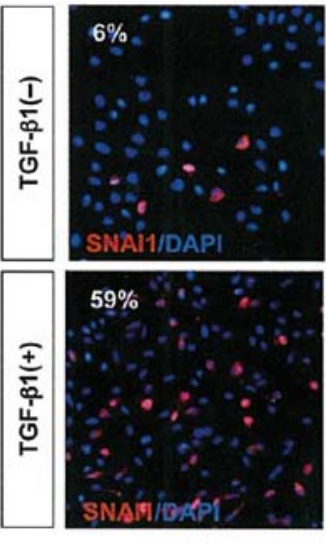

SNARI/CDH1/DAPD

Figure 2. Impact of TGF- $\beta$ on the maintenance of CSC and EMT in SW480 cells. (A), Relative expression of TGFBR1 and TGFBR3 in CD133 ${ }^{+}$cells and CD133 SW480 cells. (B), Immunofluorescence of TGFBR1 and TGFBR3 in SW480 cells. The nuclei were stained with DAPI. (C), Percentages of CD133 ${ }^{+}$cells in CD133 ${ }^{+}$ SW480 cells in the presence or absence of TGF- $\beta 1$ treatment for $48 \mathrm{~h}$. (D), Altered expression of SNAI1 and CDH1 in SW480 cells by treatment with TGF- $\beta$. (E), Relative expressions of $C D H 1$ and VIM in the $\mathrm{CD}_{133^{+}}$cells in the presence or absence of TGF- $\beta$ treatment. (F), SNAI1 expression in sphere derived from CD133 ${ }^{+}$ SW480 cells in the presence or absence of TGF- $\beta$ treatment.

Based on these results, we hypothesized that CSCs may have high sensitivity to TGF- $\beta$. TGF- $\beta$ and its family members have been implicated in the development and maintenance of stem cells (20) and the induction of EMT (21). Then, we treated CD133 ${ }^{+}$SW480 cells with TGF- $\beta 1$ and found that TGF- $\beta 1$ maintained the population of $\mathrm{CD}_{133^{+}} \mathrm{SW} 480$ cells more than in the absence of TGF- $\beta 1$ (Fig. $2 \mathrm{C}$ ). In the culturing dish, only $6 \%$ of cells endogenously expressed SNAI1; however, when treated with TGF- $\beta 1,59 \%$ of SW480 cells showed positive immunoreactivity against SNAI1 with loss of CDH1 expression at the cell-cell borders (Fig. 2D) with increased levels of VIM expression (Fig. 2E). Moreover, the induction of TGF- $\beta$-mediated EMT was confirmed by the finding the SNAI1-positive cells only at the tumor sphere surface (Fig. 2F). Similar results were detected in the experiments using a colorectal CSC differentiation model (unpublished data). Comparative studies of gene expressions of TGF- $\beta$ receptors and TGF- $\beta$-induced EMT in CD133 ${ }^{+}$and CD133-cells were also examined in the other human CRC cell lines; however, we could not find any significant differences as was detected in SW480 cells (data not shown).

SNAII mediates the re-acquisition of CSC-like properties in vitro and in vivo. Restoration of SNAI1-expression in CD133 SW480 cells was performed to investigate the impact of EMT on the restoration of CSC-like properties. In SW480 cells, an increased population of $\mathrm{CD} 133^{+}$cells was detected when pSNAI1 was transduced into CD133- SW480 cells (Fig. 3A). The change in the mRNA levels of CDH1 was significant between CD133-EV and CD133-pSNAI1 cells; however, there was no significant change in the mRNA levels of VIM, CDX2 and $M U C 2$ (Fig. 3B).

Restoration of the stemness was supported by the results of a limiting dilution assay, in which frequency of development of subcutaneous tumors was significantly higher in CD133pSNAI1 cells than in the tumors derived from CD133-EV cells (Fig. 3C). In addition, transduction of pSNAI1 effectively increased the activities of cell motility, invasion and up-regulated the $M M P 2$ levels (Fig. 3D-F). In the mouse xenografts derived from CD133-pSNAI1 cells, the cancer cells showed infiltration into the stroma and formed TB-like structures with a high frequency of $\mathrm{CD} 133^{+}$cells (Fig. 3G). Furthermore, CD133-pSNAI1 cells showed high TGFBR1 expression and the stromal cells demonstrated SMA expression (Fig. 3G). These findings suggest that transduction of SNAI1 strongly enhances not only the restoration of CSC properties but also the formation of tumor buds.

Induction of SNAII at the invasive front correlates with formation of tumor buds and metachronous lymph node metastasis. The obtained data suggested that the mediation by TGF- $\beta$ and 
A

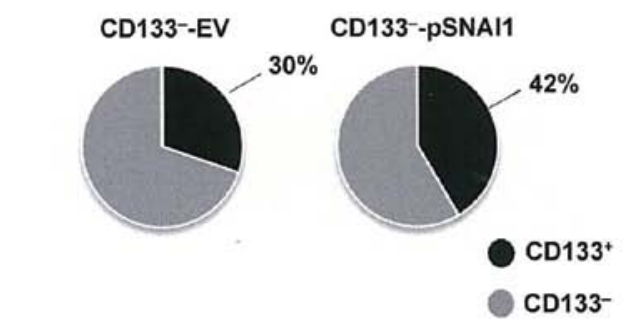

C

\begin{tabular}{|c|c|c|}
\hline \multicolumn{3}{|c|}{ Number of tumors/numbers of injections } \\
\hline Cells per & CD133--EV & CD133--pSNAl1 \\
\hline Injection & Incidence (\%) & Incidence (\%) \\
\hline $1 \times 10^{7}$ & $4 / 4 \quad(100)$ & N.E. $(100)$ \\
\hline $1 \times 10^{6}$ & $6 / 6(100)$ & $2 / 2(100)$ \\
\hline $1 \times 10^{5}$ & $6 / 6(100)$ & $4 / 4 \quad(100)$ \\
\hline $1 \times 10^{4}$ & $5 / 6 \quad(83)$ & $4 / 4 \quad(100)$ \\
\hline $1 \times 10^{3}$ & $3 / 4 \quad(75)$ & $4 / 4 \quad(100)$ \\
\hline Frequency & $1 / 3298$ & $>1 / 418^{*}$ \\
\hline
\end{tabular}

G
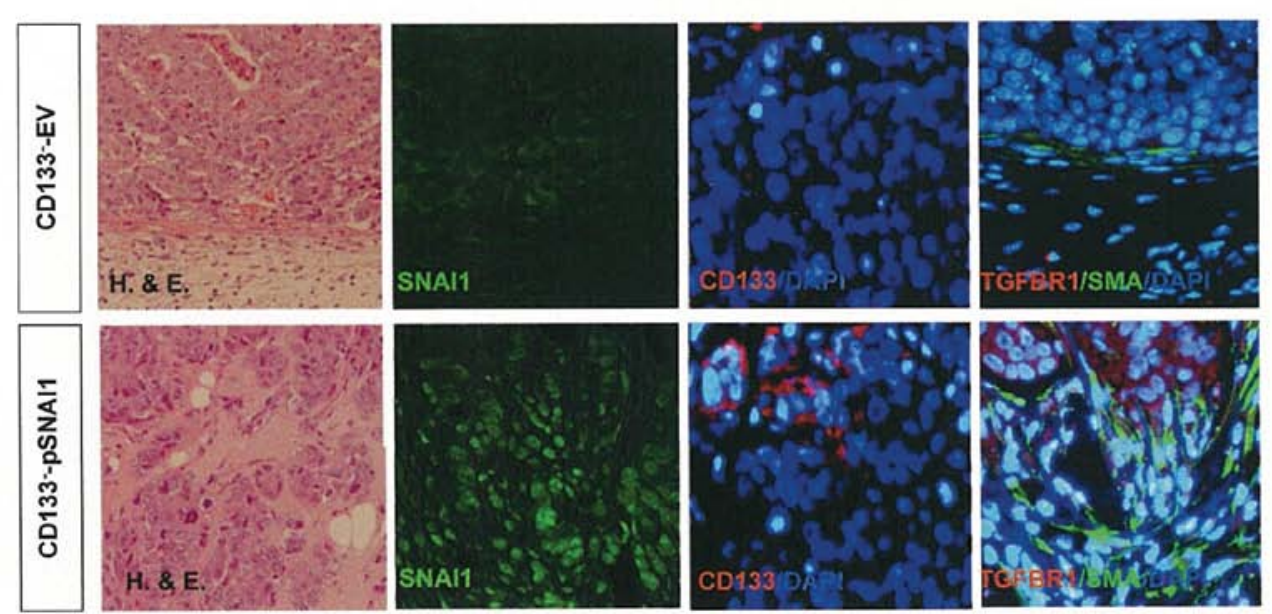

Figure 3. Induction of SNAI1 restores CSC-like properties in SW480 cells. (A), Percentages of CD133+ cells in CD133-EV and CD133-pSNAI1 cells 48 h post-transfection. (B), Expressions of EMT (CDH1 and vimentin) and colon markers (CDX2 and MUC2) in CD133-EV and CD133-pSNAI1 cells. (C), Results of limiting dilution assay of CD133-EV and CD133-pSNAI1. Initiating cell frequency was calculated using ELDA as described in Materials and methods. Included in calculation, assumption of $100 \mathrm{CD} 133^{-}$-pSNAI1 cells initiate 0 tumor in 4 injections. (D and E), Results of migration assay (D), invasion assay (E) and $M M P 2$ and MMP9 expression (F) in CD133-EV and CD133-pSNAI1 cells. (G), Histological examination (H\&E) and immunofluorescence of SNAI1, CD133, TGFBR1 and SMA in s.c. xenografts derived from CD133-EV and CD133-pSNAI1 cells. The nuclei were stained with DAPI.

subsequent induction of SNAI1 in CRC cells were necessary for the maintenance of the restoration of CSC-like properties. Therefore, we examined the association of SNAI1 expression and TB formation at the invasive front of 59 cases of stage II CRC. Interestingly, the incidence of $\mathrm{TB}$ at the invasive front in CRC cases with metachronous lymph node metastasis was higher than that in those without metachronous lymph node metastasis (Fig. 4A and B). Supporting this, CDX2-positive $\mathrm{CRC}$ cells were detected not only in the carcinoma-derived gland structures but also in the budding areas; however, SNAI1- positive CRC cells were detected only in the budding areas but not in the main tumor (Fig. 4A). These findings suggest the possibility that TB formation at the invasive front is associated with SNAI1-mediated EMT.

\section{Discussion}

According to the CSC hypothesis, tumors possess a hierarchical organization of cells, among which a subpopulation of stem-like cells is responsible for sustaining tumor growth 
A

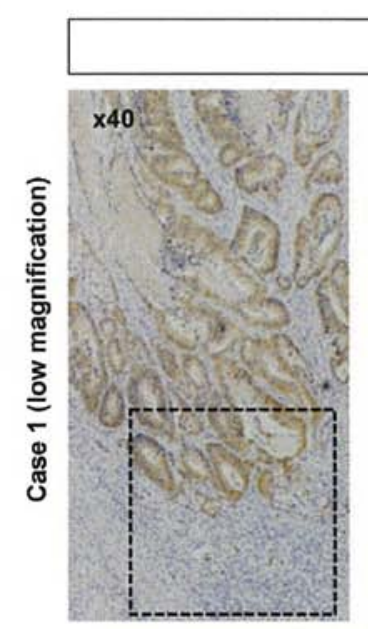

\section{$\operatorname{CDX} 2$}
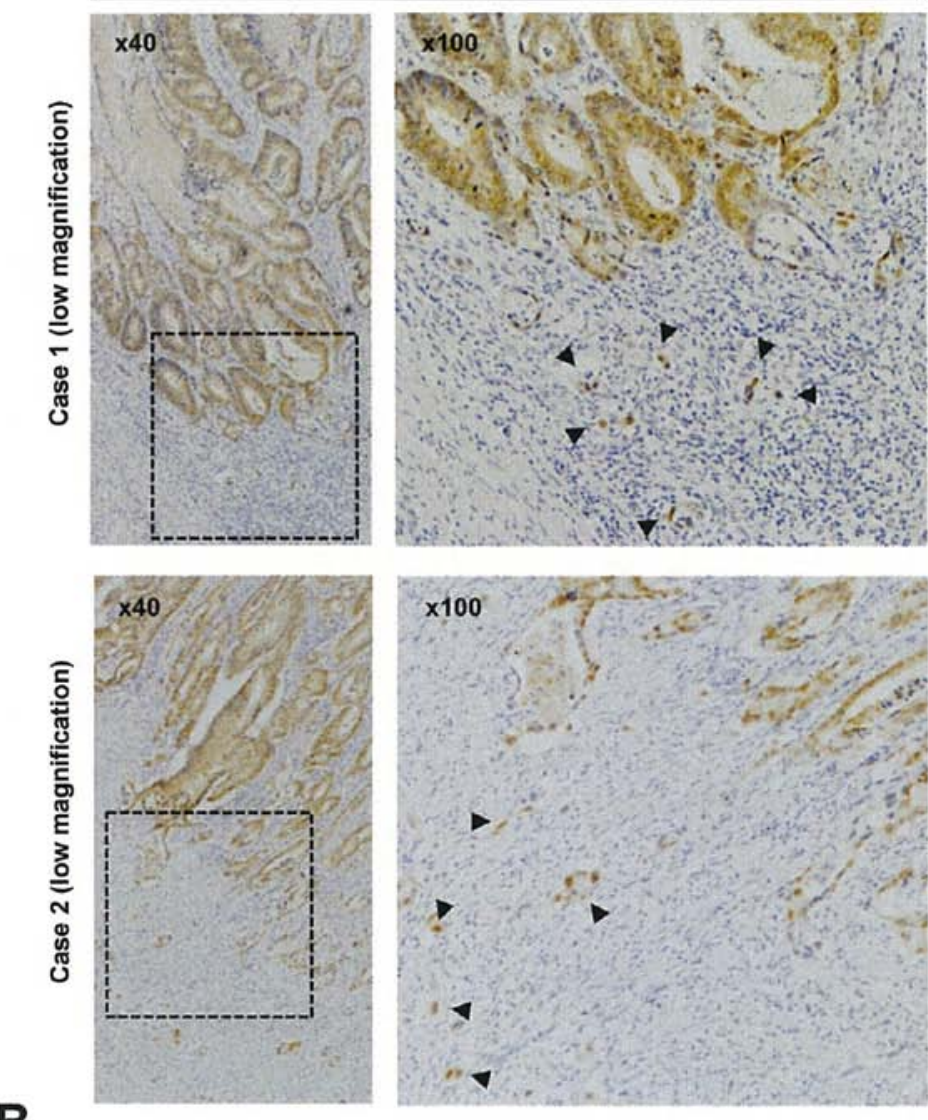

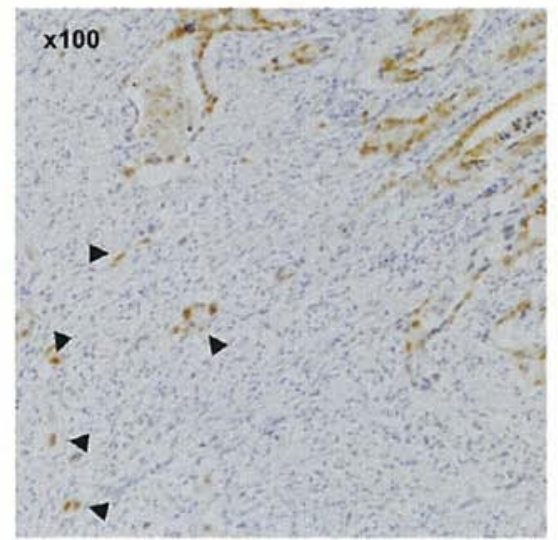

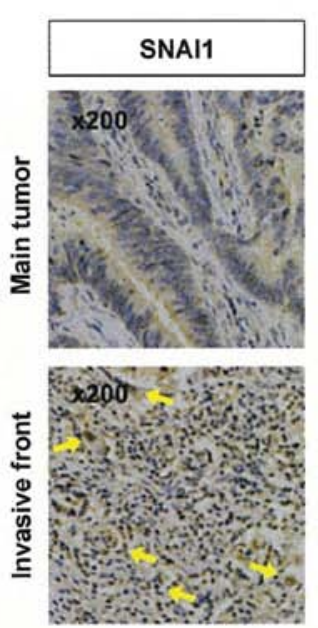
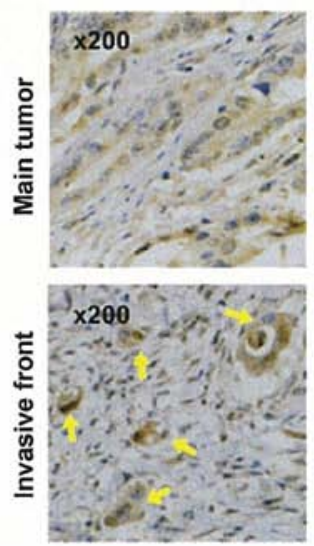

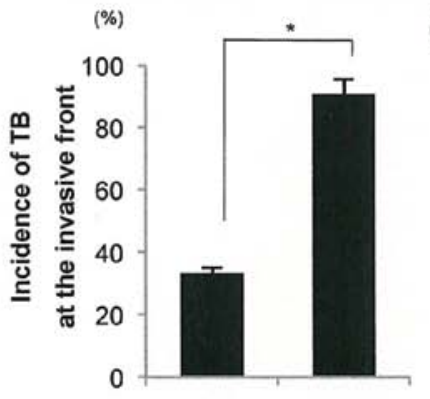

$(-)$

$(+)$
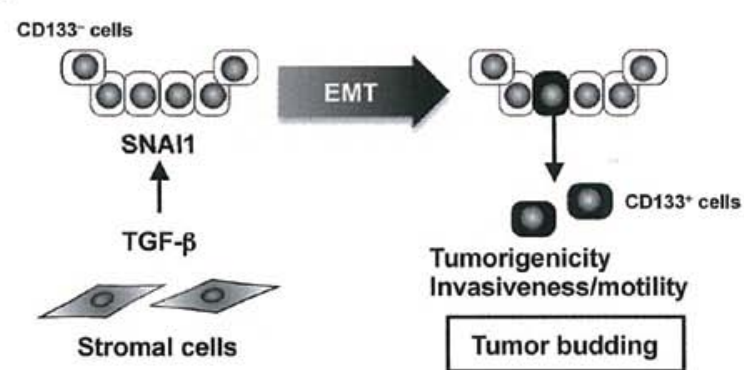

Figure 4. Expression of SNAI1 at the invasive front of CRC correlates with TB and the incidence of lymph node metastasis. (A), Expression of CDX2 and SNAI1 at the invasive front and the main tumor of case 1 (upper panel) and case 2 (lower panel). Arrows indicate representative tumor buds. (B), Incidence of TB at the invasive front of stage II CRC. The incidence of lymph node metastasis was closely correlated with TB at the invasive front. (C), A schematic model of TB induced by TGF- $\beta$ in CRC. In normal colorectal mucosa, TGF- $\beta$ supplied from stromal cells maintains stem cells located at the bottom of the epithelial crypt. Also, TGF- $\beta$ at the invasive front of CRC suppresses the differentiation process by inducing SNAI1-mediated EMT, resulting in restoration of CSC-like properties and formation of TB.

$(22,23)$. In this study, we analyzed the nature of colorectal CSCs to elucidate the relation with TB formation. In SW480 cells, $\mathrm{CD}_{133^{+}}$cells demonstrated high tumorigenicity and pluripotency, whereas $\mathrm{CD} 133^{+}$cells did not express the other CSC markers CD44 and Lgr5 in CRC-derived cell lines. In addition, various populations of $\mathrm{CD} 133^{+}$cells were detected in CRC-derived cell lines (0.1-22.54\%). Nevertheless, in a colorectal CSC differentiation model, transduction of pCDX2 into $\mathrm{CD}_{133}{ }^{+} \mathrm{SW} 480$ cells effectively decreased CD133 levels and tumorigenic potential. CD133 is a $115-120 \mathrm{kDa}$ five-transmembrane domain glycoprotein that was originally identified as a novel protein specifically localizing in micro- villi of the apical surface of mouse neuroepithelial cells (24), and the cytoplasmic domain of CD133 can be phosphorylated by Src-family tyrosine kinases (25). Although the biological functions of CD133 are not well understood, the association with the TGF- $\beta$ signaling pathway and high tumor-forming capability of $\mathrm{CD} 133^{+}$SW480 cells strongly support the idea that this glycoprotein would be useful as a molecular target for the diagnosis and treatment of CRC. Thus, we concluded that CD133 is available for the identification of CSCs in SW480 cells.

In this study, we found that $\mathrm{CD} 133^{+} \mathrm{SW} 480$ cells expressed high levels of SNAII, TGFBRI and TGFBR3 transcripts. 
Interestingly, we found that treatment with TGF- $\beta 1$ up-regulated SNAI1 expression in SW480 cells with the induction of EMT. Of note, the increase in SNAI1 expression was not distributed homogeneously, but the number of SNAI1 ${ }^{+} \mathrm{SW} 480$ cells was significantly increased in Petri dishes and in tumor spheres in Matrigel. Taken together with the fact that TGF- $\beta 1$ restored $\mathrm{CD} 133^{+} \mathrm{SW} 480$ cells, these findings suggested that induction of SNAI1 by TGF- $\beta$ may be closely related with restoration and maintenance of CSC properties (26). Supporting this idea, transduction of pCDX2 into CD133 ${ }^{+}$ SW480 cells effectively suppressed TGFBR1 and TGFBR3 expression but treatment with TGF- $\beta$ restored CD133 ${ }^{+} \mathrm{SW} 480$ cells and induced EMT. TGF- $\beta$ did not necessarily induce EMT in the other CRC-derived cell lines, which is probably associated with expression levels of TGFBR1 and TGFBR3. Moreover, transduction of pSNAI1 into CD133- SW480 cells effectively up-regulated $\mathrm{CD} 133^{+}$cells with high tumorigenic potential in the mouse xenograft model and simultaneously increased cell motility/invasiveness and MMP2 expression. Activation of the SMAD signaling by TGF- $\beta$ directly induces the expression of SNAI1, which subsequently suppresses CHD1 expression by direct binding to the E2-box sequence of the $C D H 1$ promoter (27). The evidence indicates that TGF- $\beta$-mediated maintenance of CSC-like properties may overlap EMT. Based on this body of evidence, we are currently attempting to identify novel molecular markers that are capable of identifying colorectal CSCs.

Finally, we considered that the restoration of stemness could be induced by the surrounding microenvironment in CRC tissues: i.e., TGF- $\beta$-induced EMT at the invasive front of CRC is closely correlated with the morphological alteration of tumor cells known as 'TB'. A previous study on patients with pT1 CRC showed that TGF- $\beta$-positive cells were observed in $91.7 \%$ of patients with presence of TB at the front of invasion, and there was a statistically significant correlation between the presence of lymph node metastasis and the positive expression of TGF- $\beta$ (28). Furthermore, it has been reported that CD133 expression in colorectal carcinoma is an independent prognostic marker that correlates with low rate of survival (29). In our findings, SNAI1 expression was significantly correlated with TB formation at the invasive front and the incidence of metachronous lymph node metastasis. Consequently, we therefore conclude that TGF- $\beta$ dissolved in the CRC microenvironment may participate in the SNAI1-induced EMT and restoration of CSC-like properties, which may cause metachronous metastasis in patients with stage II CRC (Fig. 4C). Detection of TB at the invasive front of CRC must be generalized for the accurate evaluation of prognosis of patients with CRC.

\section{Acknowledgements}

This work was supported by Grants-in-Aid for Scientific Research (C-19590347 and C-21590370) from the Japan Society for Promotion of Science. Yusra was supported by the scholarship from the Government of the Republic of Indonesia (IP-530).

\section{References}

1. Imai T: The growth of human carcinoma: a morph anal. Fukuoka Igaku Zasshi 45: 72-102, 1954.
2. Ueno H, Murphy J, Jass JR, Mochizuki H and Talbot IC: Tumour 'budding' as an index to estimate the potential of aggressiveness in rectal cancer. Histopathology 40: 127-132, 2002.

3. Shirouzu K, Isomoto H, Morodomi T, Ogata Y, Akagi Y and Kakegawa T: Primary linitis plastica carcinoma of the colon and rectum. Cancer 74: 1863-1868, 1994.

4. Ueno H,MochizukiH,Hashiguchi Y, Shimazaki H,Aida S, Hase K, Matsukuma S, Kanai T, Kurihara H, Ozawa K, Yoshimura K and Bekku S: Risk factors for an adverse outcome in early invasive colorectal carcinoma. Gastroenterology 127: 385-394, 2004.

5. Pardal R, Clarke MF and Morrison SJ: Applying the principles of stem-cell biology to cancer. Nat Rev Cancer 3: 895-902, 2003.

6. Phesse TJ and Clarke AR: Normal stem cells in cancer prone epithelial tissues. Br J Cancer 100: 221-227, 2009.

7. Barker N, van Es JH, Kuipers J, Kujala P, van den Born M, Cozijnsen M, Haegebarth A, Korving J, Begthel H, Peters PJ and Clevers H: Identification of stem cells in small intestine and colon by marker gene Lgr5. Nature 449: 1003-1007, 2007.

8. Sato T, Vries RG, Snippert HJ, van de Wetering M, Barker N, Stange DE, van Es JH, Abo A, Kujala P, Peters PJ and Clevers H: Single Lgr5 stem cells build crypt-villus structures in vitro without a mesenchymal niche. Nature 459: 262-265, 2009.

9. Vermeulen L, Todaro M, De Sousa Mello F, Sprick MR, Kemper K, Perez Alea M, Richel DJ, Stassi G and Medema JP: Single-cell cloning of colon cancer stem cells reveals a multilineage differentiation capacity. Proc Natl Acad Sci USA 105: 13427-13432, 2008.

10. Yeung TM, Gandhi SC, Wilding JL, Muschel R and Bodmer WF: Cancer stem cells from colorectal cancer-derived cell lines. Proc Natl Acad Sci USA 107: 3722-3727, 2010.

11. Carpentino JE, Hynes MJ, Appelman HD, Zheng T, Steindler DA, Scott EW and Huang EH: Aldehyde dehydrogenase-expressing colon stem cells contribute to tumorigenesis in the transition from colitis to cancer. Cancer Res 69: 8208-8215, 2009.

12. O'Brien CA, Pollett A, Gallinger S and Dick JE: A human colon cancer cell capable of initiating tumour growth in immunodeficient mice. Nature 445: 106-110, 2007.

13. Zhu L, Gibson P, Currle DS, Tong Y, Richardson RJ, Bayazitov IT, Poppleton H, Zakharenko S, Ellison DW and Gilbertson RJ: Prominin 1 marks intestinal stem cells that are susceptible to neoplastic transformation. Nature 457: 603-607, 2009.

14. Ricci-Vitiani L, Lombardi DG, Pilozzi E, Biffoni M, Todaro M, Peschle $\mathrm{C}$ and De Maria R: Identification and expansion of human colon-cancer-initiating cells. Nature 445: 111-115, 2007.

15. Kojima M, Ishii G, Atsumi N, Fujii S, Saito N and Ochiai A: Immunohistochemical detection of CD133 expression in colorectal cancer: a clinicopathological study. Cancer Sci 99: 1578-1583, 2008.

16. Horst D, Kriegl L, Engel J, Kirchner T and Jung A: CD133 expression is an independent prognostic marker for low survival in colorectal cancer. Br J Cancer 99: 1285-1289, 2008.

17. Usami Y, Satake S, Nakayama F, Matsumoto M, Ohnuma L, Komori T, Semba S, Ito A and Yokozaki H: Snail-associated epithelial-mesenchymal transition promotes oesophageal squamous cell carcinoma motility and progression. J Pathol 215: 330-339, 2008

18. Hu Y and Smyth GK: ELDA: extreme limiting dilution analysis for comparing depleted and enriched populations in stem cell and other assays. J Immunol Methods 347: 70-78, 2009.

19. Guo RJ, Suh ER and Lynch JP: The role of Cdx proteins in intestinal development and cancer. Cancer Biol Ther 3: 593-601, 2004.

20. Watabe $\mathrm{T}$ and Miyazono K: Roles of TGF- $\beta$ family signaling in stem cell renewal and differentiation. Cell Res 19: 103-115, 2009.

21. Miettinen PJ,Ebner R, Lopez AR and Derynck R: TGF- $\beta$ induced transdifferentiation of mammary epithelial cells to mesenchymal cells: involvement of type I receptors. J Cell Biol 127: 2021-2036, 1994.

22. Sting $J$ and Caldas C: Molecular heterogeneity of breast carcinomas and the cancer stem cell hypothesis. Nat Rev Cancer 7: 791-799, 2007.

23. Visvader JE and Lindeman GJ: Cancer stem cells in solid tumours: accumulating evidence and unresolved questions. Nat Rev Cancer 8: 755-768, 2008

24. Weigmann A, Corbeil D, Hellwig A and Huttner WB: Prominin, a novel microvilli-specific polytopic membrane protein of the apical surface of epithelial cells, is target to plasmalemmal protrusions of non-epithelial cells. Proc Natl Acad Sci USA 94: 12425-12430, 1997. 
25. Boivin D, Labbe D, Fontaine N, Lamy S, Beaulieu E, Gingras D and Béliveau R: The stem cell marker CD133 (prominin-1) is phosphorylated on cytoplasmic tyrosine-828 and tyrosine-852 by Src and Fyn tyrosine kinases. Biochemistry 48: 3998-4007, 2009.

26. Peñuelas S, Anido J, Prieto-Sánchez RM, Folch G, Barba I, Cuartas I, García-Dorado D, Poca MA, Sahuquillo J, Baselga J and Seoane J: TGF- $\beta$ increases glioma-initiating cell self-renewal through the induction of LIF in human glioblastoma. Cancer Cell 15: 315-327, 2009.

27. Cano A, Pérez-Moreno MA, Rodrigo I, Locascio A, Blanco MJ, Del Barrio MG, Portillo F and Nieto MA: The transcription factor Snail controls epithelial-mesenchymal transitions by repressing E-cadherin expression. Nat Cell Biol 2: 76-83, 2000.
28. Guzinska-Ustymowicz $\mathrm{K}$ and Kemona A: Transforming growth factor beta can be a parameter of aggressiveness of pT1 colorectal cancer. World J Gastroenterol 11: 1193-1195, 2005.

29. Horst D, Scheel SK, Liebmann S, Neumann J, Maatz S, Kirchner T and Jung A: The cancer stem cell marker CD133 has high prognostic impact but unknown functional relevance for the metastasis of human colon cancer. J Pathol 219: 427-434, 2009. 